EGU2020-9163, updated on 08 Oct 2020

https://doi.org/10.5194/egusphere-egu2020-9163

EGU General Assembly 2020

(c) Author(s) 2020. This work is distributed under

the Creative Commons Attribution 4.0 License.

\title{
Mars Regolith Properties as Constrained from HP3 Mole Operations and Thermal Measurements
}

Tilman Spohn ${ }^{1,2}$, Matthias Grott ${ }^{2}$, Nils Müller ${ }^{2}$, Jörg Knollenberg ${ }^{2}$, Christian Krause ${ }^{2}$, Troy Hudson ${ }^{3}$, Robert Deen ${ }^{3}$, Eloise Marteau ${ }^{3}$, Matthew Golombek ${ }^{3}$, Kenneth Hurst ${ }^{3}$, Sylvain Piqueux ${ }^{3}$, Susanne Smrekar ${ }^{3}$, Ann Louise Thomas ${ }^{2}$, Cinzia Fantinati ${ }^{2}$, Roy Lichtenheldt ${ }^{2}$, and Torben Wippermann ${ }^{2}$

${ }^{1}$ International Space Science Institute, Bern, Switzerland

${ }^{2}$ Deutsches Zentrum für Luft- und Raumfahrt, Germany

${ }^{3}$ Jet Propulsion Laboratory, California Institute of Technology, Pasadena, USA

The Heat Flow and Physical Properties Package $\mathrm{HP}^{3}$ onboard the Nasa InSight mission has been on the surface of Mars for more than one Earth year. The instrument's primary goal is to measure Mars' surface heat flow through measuring the geothermal gradient and the thermal condunctivity at depths between 3 and $5 \mathrm{~m}$. To get to depth, the package includes a penetrator nicknamed the "Mole" equipped with sensors to precisely measure the thermal conductivity. The Mole tows a tether with printed temperature sensors; a device to measure the length of the tether towed and a tiltmeter will help to track the path of the Mole and the tether. Progress of the Mole has been stymied by difficulties of digging into the regolith. The Mole functions as a mechanical diode with an internal hammer mechanism that drives it forward. Recoil is balanced mostly by internal masses but a remaining 3 to $5 \mathrm{~N}$ has to be absorbed by hull friction. The Mole was designed to work in cohesionless sand but at the InSight landing a cohesive duricrust of at least $7 \mathrm{~cm}$ thickness but possibly $20 \mathrm{~cm}$ thick was found. Upon initial penetration to $35 \mathrm{~cm}$ depth, the Mole punched a hole about $6 \mathrm{~cm}$ wide and $7 \mathrm{~cm}$ deep into the duricrust, leaving more than a fourth of its length without hull friction. It is widely agreed that the lack of friction is the reason for the failure to penetrate further. The $\mathrm{HP}^{3}$ team has since used the robotic arm with its scoop to pin the Mole to the wall of the hole and helped it penetrate further to almost $40 \mathrm{~cm}$. The initial penetration rate of the Mole has been used to estimate a penetration resistance of $300 \mathrm{kPa}$. Attempts to crush the duricrust a few $\mathrm{cm}$ away from the pit have been unsuccessful from which a lower bound to the compressive strength of $350 \mathrm{kPa}$ is estimated. Analysis of the slope of the steep walls of the hole gave a lower bound to cohesion of $10 \mathrm{kPa}$. As for thermal properties, a measurement of the thermal conductivity of the regolith with the Mole thermal sensors resulted in $0.045 \mathrm{Wm}^{-1} \mathrm{~K}^{-1}$. The value is considerably uncertain because part of the Mole having contact to air. The $\mathrm{HP}^{3}$ radiometer has been monitoring the surface temperature next to the lander and a thermal model fitted to the data give a regolith thermal inertia of $189 \pm 10 \mathrm{~J} \mathrm{~m}^{-2} \mathrm{~K}^{-1} \mathrm{~s}^{-1 / 2}$. With best estimates of heat capacity and density, this corresponds to a thermal conductivity of 0.045 $\mathrm{Wm}^{-1} \mathrm{~K}^{-1}$, consistent with the above measurement using the Mole. The data can be fitted well with a homogeneous soil model, but observations of Phobos eclipses in March 2019 indicate that there possibly is a thin top layer of lower thermal conductivity. A model with a top $5 \mathrm{~mm}$ layer of 0.02 
Wm-1K-1 above a half-space of $0.05 \mathrm{Wm}-1 \mathrm{~K}-1$ matches the amplitudes of both the diurnal and eclipse temperature curves. Another set of eclipses will occur in April 2020. 